\title{
Fabrication of Nanohydroxyapatite/Poly(caprolactone) Composite Microfibers Using Electrospinning Technique for Tissue Engineering Applications
}

\author{
Mohd Izzat Hassan, ${ }^{1}$ Tao Sun, ${ }^{2}$ and Naznin Sultana ${ }^{1}$ \\ ${ }^{1}$ Faculty of Biosciences and Medical Engineering (FBME), Universiti Teknologi Malaysia (UTM), Johor Bahru, \\ 81310 Skudai, Johor, Malaysia \\ ${ }^{2}$ Miniaturized Medical Devices Program, Institute of Microelectronics, Agency for Science, \\ Technology and Research ( $A * S T A R)$, Singapore 117685
}

Correspondence should be addressed to Naznin Sultana; naznin@biomedical.utm.my

Received 19 March 2014; Revised 5 June 2014; Accepted 16 June 2014; Published 25 June 2014

Academic Editor: Zhongkui Hong

Copyright (C) 2014 Mohd Izzat Hassan et al. This is an open access article distributed under the Creative Commons Attribution License, which permits unrestricted use, distribution, and reproduction in any medium, provided the original work is properly cited.

\begin{abstract}
Tissue engineering fibrous scaffolds serve as three-dimensional (3D) environmental framework by mimicking the extracellular matrix (ECM) for cells to grow. Biodegradable polycaprolactone (PCL) microfibers were fabricated to mimic the ECM as a scaffold with $7.5 \%(\mathrm{w} / \mathrm{v})$ and $12.5 \%(\mathrm{w} / \mathrm{v})$ concentrations. Lower PCL concentration of 7.5\% (w/v) resulted in microfibers with bead defects. The average diameter of fibers increased at higher voltage and the distance of tip to collector. Further investigation was performed by the incorporation of nanosized hydroxyapatite (nHA) into microfibers. The incorporation of $10 \%(\mathrm{w} / \mathrm{w}) \mathrm{nHA}$ with $7.5 \%$ (w/v) PCL solution produced submicron sized beadless fibers. The microfibrous scaffolds were evaluated using various techniques. Biodegradable PCL and nHA/PCL could be promising for tissue engineering scaffold application.
\end{abstract}

\section{Introduction}

The recent advanced approach for replacing lost tissue, damaged organ, and organ failure is known as tissue engineering (TE). Scaffold or matrix is one of the elements of tissue engineering. It serves as framework for cells by providing appropriate environment to live and grow, promoting the development of an extracellular matrix and other biological molecules and by facilitating the formation of tissue and organ function. Various techniques have been investigated to produce TE scaffolds, such as freeze-drying, phase-separation, solvent casting or particulate leaching, gas foaming, electrospinning, and rapid prototyping [1-6].

In the recent years, electrospinning has gained wide interest among the researchers for producing fibers with controlled diameter, high surface area, and porous structure. It has been utilized for producing polymeric nanofibers. The technique is able to produce continuous nano- or microfibers by applying an electrostatic field to a polymer solution driven by high voltage supply between a needle tip and the collector. The advantages of electrospinning are the production of uniform and broad range of diameter of nanofibers with long and continuous characteristic compared to other techniques [5].

Biodegradable and biocompatible synthetic polymer polycaprolactone (PCL) has slower degradation rate and is a suitable candidate for fabricating fibrous scaffolds. It has been approved by Food and Drug Administration (FDA) for various medical applications. PCL can be dissolved in many solvents such as chloroform, dimethylformamide (DMF), hexafluoroisopropanol (HFIP), dichloromethane (DCM), and tetrafluoroethylene (TFE) [6-11]. However, PCL is hydrophobic. On the other hand, bioceramics such as hydroxyapatite (HA) and calcium phosphate can be incorporated with PCL to produce composite fibers through electrospinning. HA is osteoconductive and hydrophilic compared to PCL polymers. Incorporation of nHA into PCL fibers could have better properties than PCL fibers alone. 
The objectives of present work were to use the electrospinning technique to produce beadless or defect free PCL and nHA/PCL composite fibers. The effects of polymer solution concentration and other parameters of electrospinning technique on the morphology of PCL microfibers and nHA/PCL composite microfibers were also investigated.

\section{Materials and Methods}

2.1. Materials. Polycaprolactone $\left(M_{w}: 70,000-90,000\right)$ was purchased from Sigma-Aldrich. $99.8 \%$ acetone was purchased from Sigma. Hydroxyapatite nanoparticle was produced in-house from mixing acetone solution of $\mathrm{Ca}\left(\mathrm{NO}_{3}\right)_{2} \cdot 4 \mathrm{H}_{2} \mathrm{O}$ with an aqueous solution of $\left(\mathrm{NH}_{4}\right)_{2} \mathrm{HPO}_{4}$ and $\mathrm{NH}_{4} \mathrm{HCO}_{3}$ by nanoemulsion technique reported in the previous study $[12,13]$.

\subsection{Methods}

2.2.1. Preparation of PCL and $n H A / P C L$ Solutions. The PCL pellets were weighted and dissolved in acetone under magnetic stirrer at $40^{\circ} \mathrm{C}$. nHA/PCL solution was prepared by adding $10 \%(\mathrm{w} / \mathrm{w})$ of $\mathrm{nHA}$ into $7.5 \%(\mathrm{w} / \mathrm{v})$ PCL solution. The solution was then homogenized using a homogenizer IKA T25 (IKA Works) in order to disperse HA nanoparticles in the PCL polymer solution.

2.2.2. Electrospinning. The experiment of electrospinning was carried out by using an electrospinning unit (NaBond, China). The PCL and nHA/PCL solutions were transferred into a $5 \mathrm{~mL}$ syringe with a blunt-end needle of $18 \mathrm{G}$ and $22 \mathrm{G}$ in size. The feeding rate of the injection syringe was fixed at $1 \mathrm{~mL} / \mathrm{h}, 1.5 \mathrm{~mL} / \mathrm{h}, 2 \mathrm{~mL} / \mathrm{h}$, and $3 \mathrm{~mL} / \mathrm{h}$ using an infusion pump (Veryark TCV-IV), while the distance between the collector plate and the tip of blunt-end needle was set to $10 \mathrm{~cm}$ and $15 \mathrm{~cm}$. The tip of blunt needle was connected to the positive electrode of high-voltage power supply and negative electrode was connected to a metallic rack as the grounded target collector. The metallic rack was wrapped with an aluminium foil $\left(10 \times 10 \mathrm{~cm}^{2}\right)$ as a collector for collecting electrospun fibers. Electrospun fibers were ejected from the syringe onto the collector by varying high voltage DC power supply in the range of $0-30 \mathrm{kV}$. The collected electrospun membrane was then stored in a desiccator prior to analysis.

In the beginning of the experiment of the electrospinning process, the tip of the blunt-needle was observed to check any droplet of the solution. When the droplet of the solution became a large glob shape, the droplet at the tip of the needle was quickly wiped off using tissue and cotton bud to prevent clogging from the needle tip. The voltage was slowly increased and stopped until a stable Taylor cone was achieved. As the potential increased, the droplet emerged and moved towards the direction of the collector caused by electrostatic force between the needle tip and the collector.

2.2.3. Characterization. The electrospun fibers were examined under a scanning electron microscopy (SEM; Hitachi TM-3000, Japan) and a field emission scanning electron microscopy (FESEM). The fibers were cut into a square section, mounted on aluminium stub, and observed at an accelerating voltage of $15 \mathrm{kV}$. The diameters of resulting fibers were measured at random location on each fiber. At least 50 measurements from the images were recorded using image analysis software (Image J, NIH, USA). The samples were sputter coated with gold before analysis under FESEM. Energy dispersive X-ray (EDX) attached with the SEM was used to confirm the presence of HA in the PCL polymer solution.

2.2.4. Cell Viability. According to ISO 10993-5: 2009, a mouse fibroblast cell line (L929, ATCC, USA) was used to evaluate the cytotoxicity of PCL and HA/PCl microfibers. L929 cells were cultured in Eagle's minimum essential medium (EMEM, ATCC 30-2003, USA) containing 10\% (v/v) horse serum and incubated at $37^{\circ} \mathrm{C}$ in an atmosphere of $5 \% \mathrm{CO}_{2}$ and $95 \%$ humidity. When the cells were grown to $70-80 \%$ confluence, they were detached by $0.25 \%(\mathrm{w} / \mathrm{v})$ trypsinethylenediaminetetraacetic acid (trypsin-EDTA) (Invitrogen Co., USA) and counted by an automated cell counter (Luna, Logos Biosystems, USA) [14]. L929 cells were cultured at the concentration of $1 \times 10^{5}$ cells/well onto PCL and 10\% HA incorporated HA/PCL composite fibers, and then the 24-well cell culture plate containing samples was incubated at $37^{\circ} \mathrm{C}$ in an atmosphere of $5 \% \mathrm{CO}_{2}$.

To ascertain the viable and nonviable L929 cells adhering to the PCL and HA/PCL microfibers at 7 days of culture, live/dead cell staining (live/dead viability/cytotoxicity kit, Invitrogen Co., USA) was performed. Briefly, living cells were stained in green through the enzymatic conversion of the virtually nonfluorescent cell-permeant calcein-AM to the intensely fluorescent calcein (excitation/emission, $\sim 495 \mathrm{~nm} / \sim 515 \mathrm{~nm})$. EthD-1 entered cells with damaged membranes and, after binding to nucleic acids, produced a bright red fluorescence in dead cells (excitation/emission, $\sim 495 \mathrm{~nm} / \sim 635 \mathrm{~nm}$ ). After 7 days of culture, L929 cells stained in green and red were observed using a fluorescence microscope (Olympus BX61, Olympus Optical Co., Japan). Cell viability was calculated by counting the number of live cells as well as dead cells and then dividing the number of live cells by the number of total cells. At least 7 areas were randomly chosen for the cell viability assessment [14].

\section{Results and Discussions}

3.1. Electrospinning of PCL Solution. Using PCL solution in acetone, PCL fibers were obtained by electrospinning technique. Figure 1 shows the SEM micrographs of electrospun PCL microfibers at different PCL concentrations. Microfibers with $7.5 \%(\mathrm{w} / \mathrm{v})$ concentration contained beads in the fibers while the microfibers with $12.5 \%(\mathrm{w} / \mathrm{v})$ concentration had homogeneous and continuous and beadless fibers. The morphology of the fiber produced was adversely affected by the lower concentration of the PCL. Low polymer concentration affects viscosity and surface tension [15]. If the viscosity of the polymer is too low, entanglements between polymer chains become unable to provide a stable jet. Due to the surface 


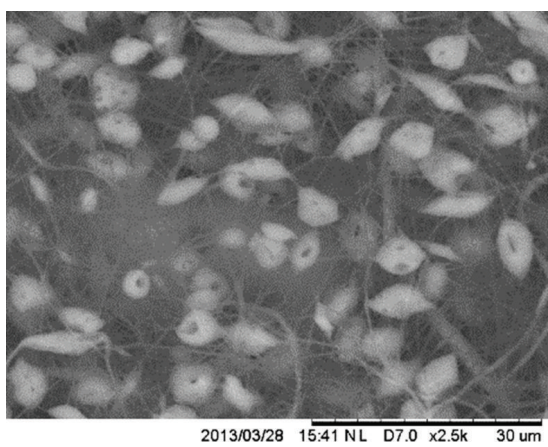

(a)

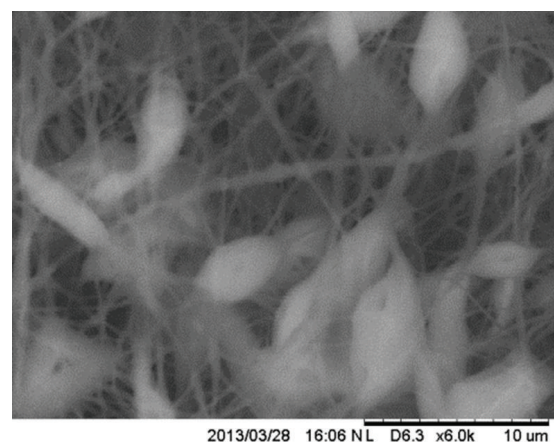

(b)

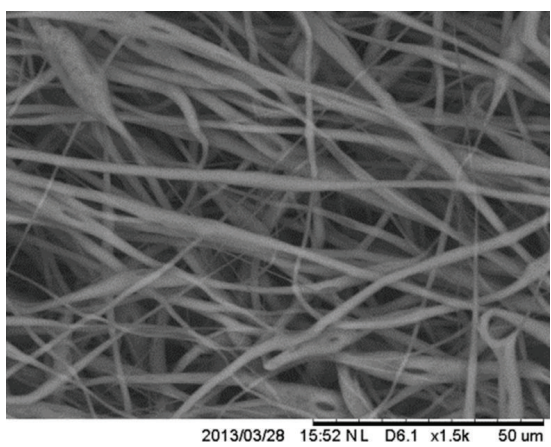

(c)

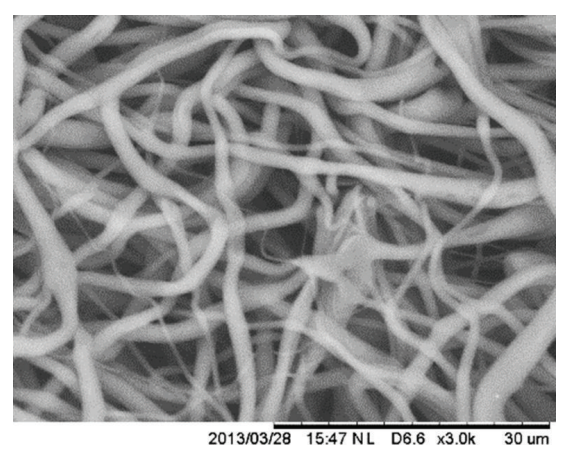

(d)

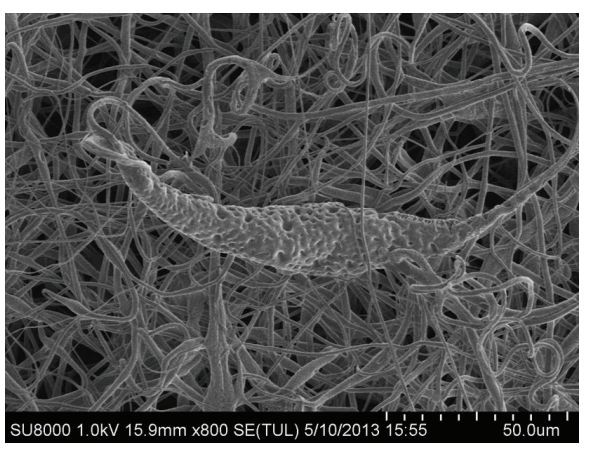

(e)

FIGURE 1: SEM micrographs of PCL fibers with 7.5\% (w/v) at (a) $10 \mathrm{~cm}$ and (b) $15 \mathrm{~cm}$ tip-collector distance while $12.5 \% \mathrm{w} / \mathrm{v}$ at (c) $15 \mathrm{kV}, 3 \mathrm{~mL} / \mathrm{h}$ and (d) $22 \mathrm{kV}, 1.5 \mathrm{~mL} / \mathrm{h}$; (e) FESEM micrograph of bead defect at $7.5 \% \mathrm{w} / \mathrm{v}$ PCL.

TABLE 1: Electrospinning parameters for PCL fiber.

\begin{tabular}{|c|c|c|c|c|c|}
\hline Concentration $(\% \mathrm{w} / \mathrm{v})$ & Diameter $(\mathrm{cm})$ & Voltage $(\mathrm{kV})$ & Flow rate $(\mathrm{mL} / \mathrm{h})$ & Average diameter & Characteristic \\
\hline 7.5 & 10 & 15 & 3 & $287.27 \mathrm{~nm}$ & Beaded \\
\hline 7.5 & 15 & 15 & 3 & $302.91 \mathrm{~nm}$ & Beaded \\
\hline 12.5 & 10 & 15 & 3 & $1.33 \mu \mathrm{m}$ & Smooth \\
\hline 12.5 & 10 & 22 & 1.5 & $2.03 \mu \mathrm{m}$ & Smooth \\
\hline
\end{tabular}

tension effect, droplets can be formed before polymer fibers deposited to the grounded collector. On the other hand, fibers cannot be formed in too concentrated polymer solution. The solution will block the needle outlet. With higher solution viscosity, larger fiber diameter is formed [15].

Although the PCL fibers of $12.5 \%(\mathrm{w} / \mathrm{v})$ concentration had smooth and continuous microstructure, the diameter of the fiber was wider than that of the microfibers produced from $7.5 \%(\mathrm{w} / \mathrm{v})$ polymer concentration. The diameter of microfibers produced from $12.5 \%(\mathrm{w} / \mathrm{v})$ was in the range of one to ten micrometers. On the other hand, fibers produced from $7.5 \%(\mathrm{w} / \mathrm{v})$ PCL concentration had the average fiber diameter of several hundred nanometers. This was in agreement with another study where it was described that lower concentration (5 and 7.5\% (w/v)) produced nanosize fibers with beading and higher concentration $(10 \%(\mathrm{w} / \mathrm{v}))$ produced micrometer-size fiber without beads [16]. The problem with lower concentration was that the resulting nanofibers had spindle-like bead characteristic. The concentration gives some trade-off between the fiber size and existence of beading along with the fibers. The beading defect as in Figures 1(a), $1(b)$, and $1(\mathrm{c})$ is the common problem which needs to be overcome for producing fibers by electrospinning. Particularly large beads with most of the spindle-like structures were obtained with an average size of $3.85 \mu \mathrm{m}$ and $3.60 \mu \mathrm{m}$ with voltage of $15 \mathrm{kV}$ and $22 \mathrm{kV}$. The sizes of the beads were in range of micrometer scale with porous surfaces. When the distance between the grounded collector and the needle tip was increased, the average fiber diameter also increased. On the other hand, the average fiber diameter increased with the decreased flow rate for $12.5 \%(\mathrm{w} / \mathrm{v})$ concentration.

Table 1 shows the influence of different polymer concentrations on fiber diameters. The flow rate and the distance were also crucial in determining the size of fiber diameter. At lower flow rate, the applied voltage was increased to achieve stable Taylor cone. Thus the larger size of fiber diameter resulted. After increasing the distance between the needle tip and the collector by $5 \mathrm{~cm}$ at low concentration, the fiber diameter was slightly increased.

The results based on the parameters given in Table 1 , it was observed that there are many parameters that needed to be adjusted to obtain nanofibers. Chloroform is commonly 
TABLE 2: Electrospinning parameters for PCL/HA fiber.

\begin{tabular}{lcccccc}
\hline Concentration $(\mathrm{w} / \mathrm{v} \%)$ & Diameter $(\mathrm{cm})$ & Voltage $(\mathrm{kV})$ & $\begin{array}{c}\text { Flow rate } \\
(\mathrm{mL} / \mathrm{h})\end{array}$ & Gauge size $(\mathrm{G})$ & $\begin{array}{c}\text { Average diameter } \\
(\mu \mathrm{m})\end{array}$ & \begin{tabular}{c} 
Characteristic \\
\hline 7.5
\end{tabular} \\
7.5 & 10 & 22 & 3 & 18 & 1.25 & Smooth \\
7.5 & 10 & 22 & 3 & 22 & 1.11 & Smooth \\
7.5 & 10 & 22 & 2 & 22 & 1.18 & Smooth \\
7.5 & 10 & 22 & 2 & 18 & 1.23 & Smooth \\
7.5 & 10 & 22 & 1 & 22 & Smooth & 1.44 \\
\hline
\end{tabular}

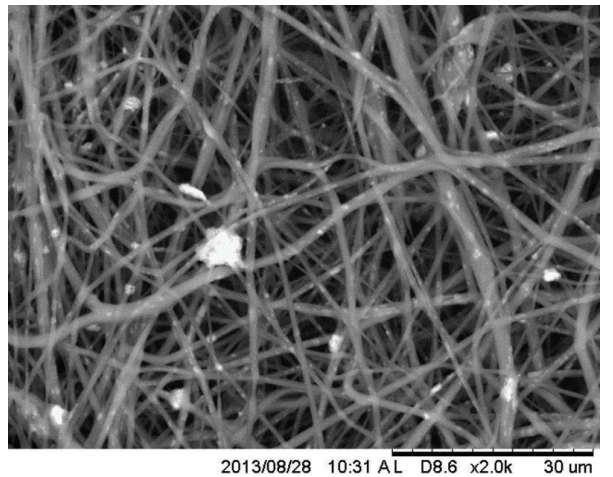

(a)

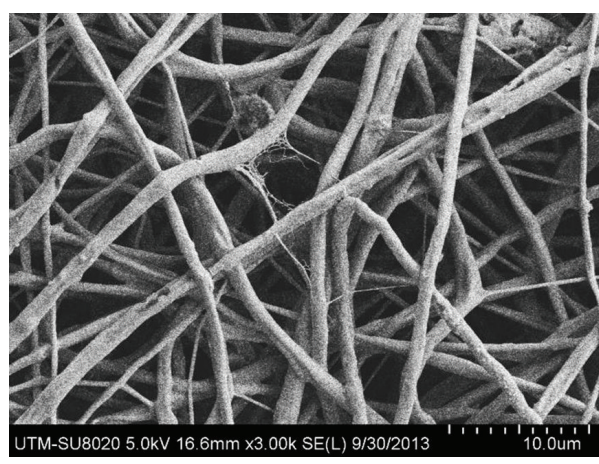

(c)

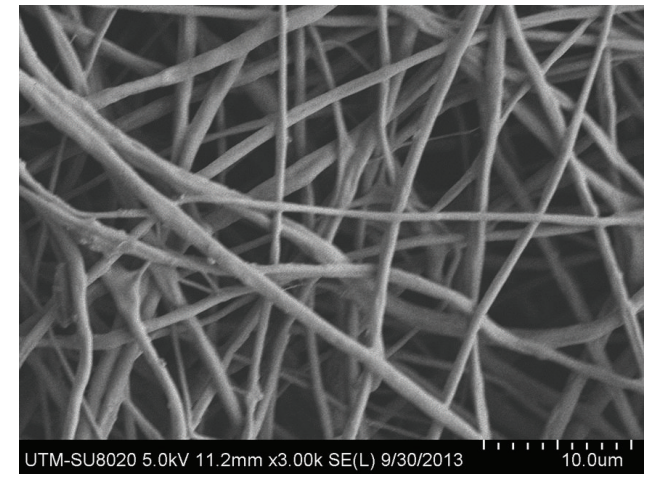

(b)

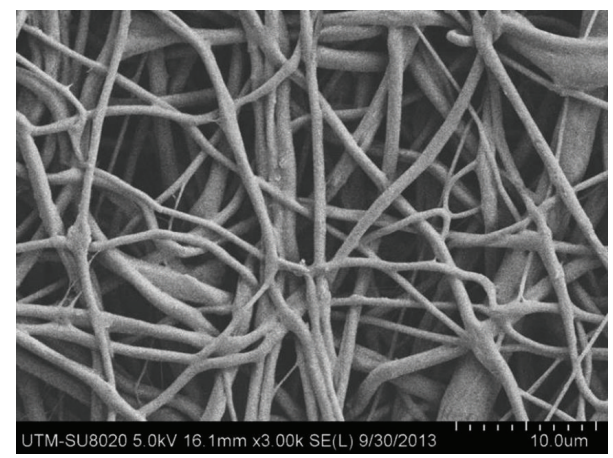

(d)

Figure 2: SEM micrograph of 10\% HA in 7.5\% (w/v) of nHA/ PCL fibers at (a) $1 \mathrm{~mL} / \mathrm{h}$ and $22 \mathrm{kV}$; FESEM micrographs at $22 \mathrm{kV}$ and flow rates of (b) $3 \mathrm{~mL} / \mathrm{h}$, (c) $2 \mathrm{~mL} / \mathrm{h}$, and (d) $1 \mathrm{~mL} / \mathrm{h}$, respectively.

used solvent for electrospinning of PCL but the diameter of fiber produced was in micrometer. However, other researchers successfully obtained fibers in nanometer scale by combining chloroform with other solvents such as chloroform/dimethylformamide, chloroform/methanol, and chloroform/acetone [17, 18]. Acetone is less harmful compared to other solvents and thus was explored in this study. However, in this study beadless or defect free fibers resulted in microscale sizes.

3.2. Electrospinning of $n H A / P C L$. Hydroxyapatite nanoparticles (nHA) were incorporated into PCL solution of $7.5 \%$ $(\mathrm{w} / \mathrm{v})$ concentration. At constant diameter and voltage, six different solutions were electrospun at 1,2, and 3 flow rates
(mL/h) using $18 \mathrm{G}$ and $22 \mathrm{G}$ blunt needle (Table 2 ). We observed that nHA was successfully incorporated along the fiber as shown in Figure 2. SEM micrographs confirmed that nHA was well mixed with PCL polymer solution and nHA was embedded well into PCL fibers. The nHA were homogenously distributed within the fibers possibly due to the low concentration of nHA. If lower concentration of $\mathrm{nHA}$ is used, it is possible to overcome the agglomeration of nanoparticles. A homogenizer was used to disperse the nHA particles throughout the fibers. The average diameter of fibers was not affected by the different parameters of flow rate and gauge size. The average diameter of fibers was in one micrometer size. Interestingly, the incorporation of nHA made the nHA/PCL fibers smoother with almost unnoticeable bead defects compared to the electrospun PCL 


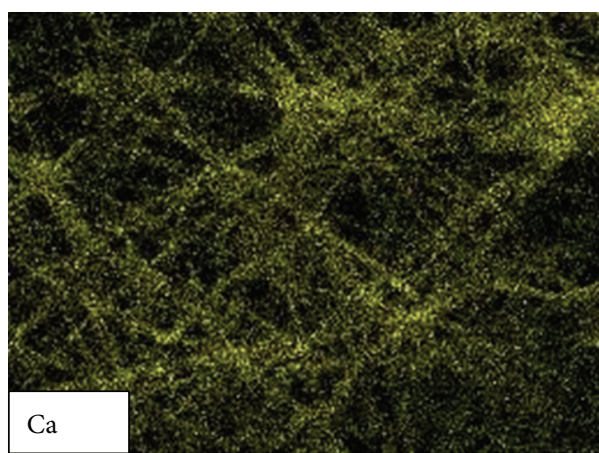

(a)

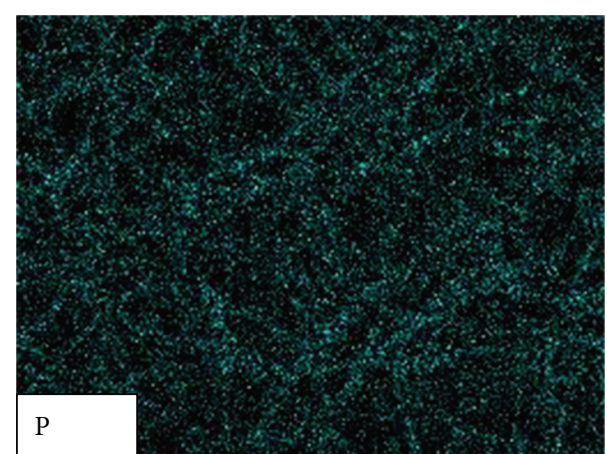

(b)

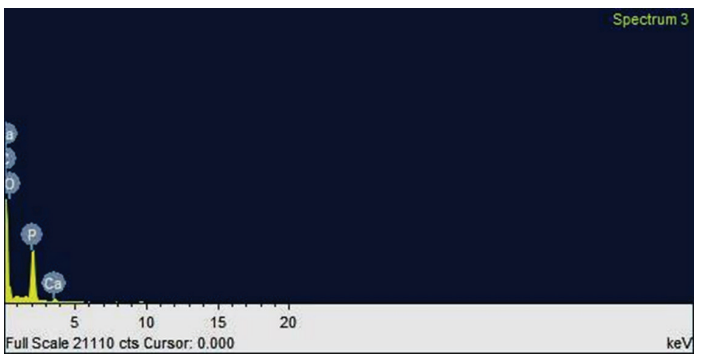

(c)

FIGURE 3: Elemental mapping of (a) calcium and (b) phosphorus and (c) EDX spectrum of 10\% HA in 7.5 w/v\% HA/PCL composite fibers at $1 \mathrm{~mL} / \mathrm{h}, 22 \mathrm{kV}$.

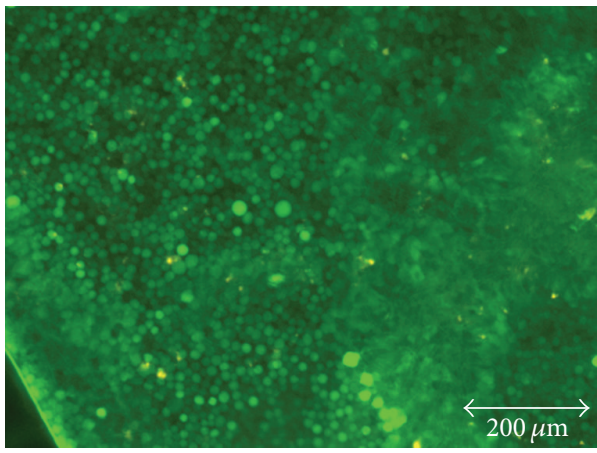

(a)

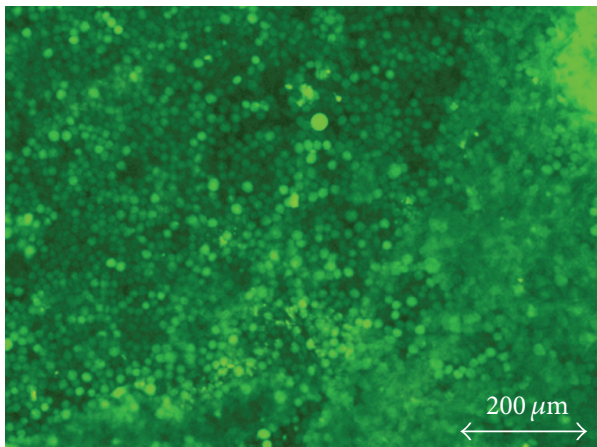

(c)

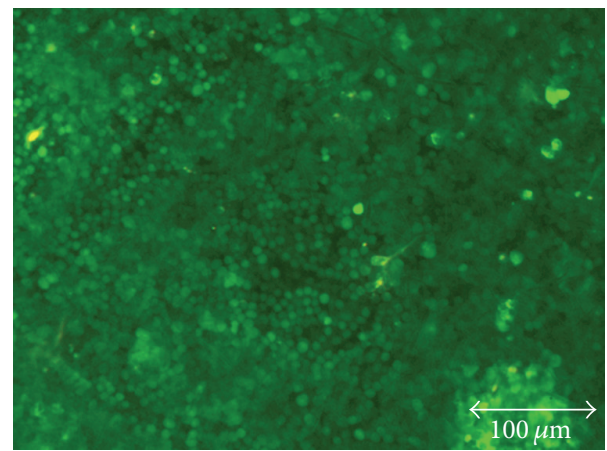

(b)

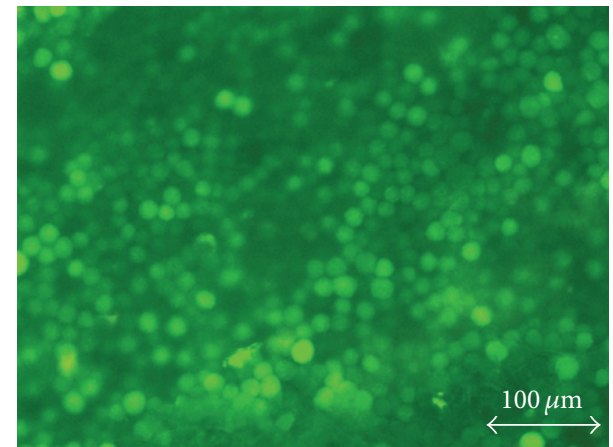

(d)

FIGURE 4: After 7 days of culture with L929 cells seeded on (a-b) PCL and (c-d) HA/PCL microfibers. 
fibers at the same concentration. However, an increase in fiber diameter was observed (from nanometer to submicron size). The result was in contrast with another study where the fiber diameter was observed to be decreased after adding nHA into PCL $[19,20]$. However, they used another solvent to produce electrospun HA/PCL nanofibers and it is well known in literature that the solvent plays an important role in fiber diameter sizes.

The elemental mapping further confirmed the distribution of nHA in PCL nanofiber matrices (Figure 3). EDX analyses at different locations of composite electrospun fibers also validated the presence of nHA particles that were well mixed with polymer fiber surfaces (Figure 3 ). The success of electrospinning of polymeric fibrous scaffolds lies in the process of preparing the suitable solution concentration and the process of electrospinning itself. The applied voltage, flow rate, and distance between the tip and the collector do effect the distribution of diameter of obtained fiber. However, producing fibers without bead defects is also needed.

In order to assess any problems associated with fabrication technique and with the materials, the in vitro cell culture was performed. It was observed that the cell viability was greater than 95\% for both PCL and HA/PCL fibers. After 7 days of culture, morphology of L929 cells adhering to PCL and HA/PCL electrospun fibers was shown in Figure 4. At day 7, L929 cells had grown into a confluent state and formed a monolayer. L929 cells mainly exhibited a round morphology on the surface of PCL fibers. On the cell surface, many nodules were also observed. The live/dead assay exhibited that more than 95\% cells adhering to both PCL and HA/PCL fibers were viable and metabolically active (Figure 4 ). This indicates the cytocompatibility of the PCL and HA/PCL microfibers.

\section{Conclusions}

PCL nanofibers were obtained at lower concentration of 7.5\% $(\mathrm{w} / \mathrm{v})$ PCL polymer concentration with beads. At higher concentration of $12.5 \%(\mathrm{w} / \mathrm{v})$, beadless fibers with submicron size were produced. Incorporation of nHA produced beadless fibers without agglomeration. However, the incorporation of nHA made the fibers thicker than those of PCL nanofibers. Result of cell viability showed PCL and HA/PCL electrospun fibers were nontoxic and safe for the practical application. The electrospun nHA/PCL is expected to be conducive for cell growth as it contains osteoconductive nHA that has the bone bonding ability to be used as tissue engineering fibrous scaffolds.

\section{Conflict of Interests}

The authors declare that there is no conflict of interests.

\section{Acknowledgments}

The authors would like to acknowledge the Faculty of Biosciences and Medical Engineering, Mediteg lab, Universiti Teknologi Malaysia (UTM), for the lab facilities. This work was supported by research Grants FRGS (vot no. 4F126), GUP Tier 1 (05H07, 06H84). Authors also acknowledge the support provided by MOHE, RMC, and UTM.

\section{References}

[1] N. Sultana and T. H. Khan, "Polycaprolactone scaffolds and hydroxyapatite/polycaprolactone composite scaffolds for bone tissue engineering," Journal of Bionanoscience, vol. 7, no. 2, pp. 169-173, 2013.

[2] N. Sultana and T. H. Khan, "Water absorption and diffusion characteristics of nanohydroxyapatite (nHA) and poly(hydroxybutyrate-co-hydroxyvalerate-) based composite tissue engineering scaffolds and nonporous thin films," Journal of Nanomaterials, vol. 2013, Article ID 479109, 8 pages, 2013.

[3] Z.-L. Mou, L.-M. Duan, X.-N. Qi, and Z.-Q. Zhang, "Preparation of silk fibroin/collagen/hydroxyapatite composite scaffold by particulate leaching method," Materials Letters, vol. 105, pp. 189-191, 2013.

[4] C. Ji, N. Annabi, M. Hosseinkhani, S. Sivaloganathan, and F. Dehghani, "Fabrication of poly-DL-lactide/polyethylene glycol scaffolds using the gas foaming technique," Acta Biomaterialia, vol. 8, no. 2, pp. 570-578, 2012.

[5] L. van der Schueren, B. de Schoenmaker, Ö. I. Kalaoglu, and K. de Clerck, "An alternative solvent system for the steady state electrospinning of polycaprolactone," European Polymer Journal, vol. 47, no. 6, pp. 1256-1263, 2011.

[6] T. Serra, J. A. Planell, and M. Navarro, "High-resolution PLAbased composite scaffolds via 3-D printing technology," Acta Biomaterialia, vol. 9, no. 3, pp. 5521-5530, 2013.

[7] K. T. Shalumon, K. H. Anulekha, K. P. Chennazhi, H. Tamura, S. V. Nair, and R. Jayakumar, "Fabrication of chitosan/poly(caprolactone) nanofibrous scaffold for bone and skin tissue engineering," International Journal of Biological Macromolecules, vol. 48, no. 4, pp. 571-576, 2011.

[8] J. O. Zoppe, M. S. Peresin, Y. Habibi, R. A. Venditti, and O. J. Rojas, "Reinforcing poly( $\varepsilon$-caprolactone) nanofibers with cellulose nanocrystals," ACS Applied Materials and Interfaces, vol. 1, no. 9, pp. 1996-2004, 2009.

[9] M. Simşek, M. Capkın, A. Karakeçili, and M. Gümüşderelioğlu, "Chitosan and polycaprolactone membranes patterned via electrospinning: effect of underlying chemistry and pattern characteristics on epithelial/fibroblastic cell behavior," Journal of Biomedical Materials Research A, vol. 100, no. 12, pp. 33323343, 2012.

[10] T.-H. Nguyen, T. Q. Bao, I. Park, and B.-T. Lee, "A novel fibrous scaffold composed of electrospun porous poly (epsiloncaprolactone) fibers for bone tissue engineering," Journal of Biomaterials Applications, vol. 28, no. 4, pp. 514-528, 2013.

[11] Z. Chen, L. Cao, L. Wang, H. Zhu, and H. Jiang, "Effect of fiber structure on the properties of the electrospun hybrid membranes composed of poly( $\varepsilon$-caprolactone) and gelatin," Journal of Applied Polymer Science, vol. 127, no. 6, pp. 4225-4232, 2013.

[12] M. I. Hassan, M. Mokhtar, N. Sultana, and T. H. Khan, "Production of hydroxyapatite(HA) nanoparticle and HA/PCL tissue engineering scaffolds for bone tissue engineering," in Proceedings of the IEEE EMBS Conference on Biomedical Engineering and Sciences (IECBES '12), pp. 239-242.

[13] W. Y. Zhou, M. Wang, W. L. Cheung, B. C. Guo, and D. M. Jia, "Synthesis of carbonated hydroxyapatite nanospheres 
through nanoemulsion," Journal of Materials Science: Materials in Medicine, vol. 19, no. 1, pp. 103-110, 2008.

[14] T. Sun, T. H. Khan, and N. Sultana, "Fabrication and in vitro evaluation of nanosized hydroxyapatite/chitosan-base d tissue engineering scaffolds," Journal of Nanomaterials, vol. 2014, Article ID 194680, 8 pages, 2014.

[15] D. H. Reneker and I. Chun, "Nanometre diameter fibres of polymer, produced by electrospinning," Nanotechnology, vol. 7, no. 3, pp. 216-223, 1996.

[16] L. A. Bosworth and S. Downes, "Acetone, a sustainable solvent for electrospinning poly ( $\varepsilon$-caprolactone) fibres: effect of varying parameters and solution concentrations on fibre diameter," Journal of Polymers and the Environment, vol. 20, no. 3, pp. 879886, 2012.

[17] Z. X. Meng, W. Zheng, L. Li, and Y. F. Zheng, "Fabrication and characterization of three-dimensional nanofiber membrance of PCL-MWCNTs by electrospinning," Materials Science and Engineering C, vol. 30, no. 7, pp. 1014-1021, 2010.

[18] T. Amna, N. A. M. Barakat, M. S. Hassan, M. Khil, and H. Y. Kim, "Camptothecin loaded poly( $\varepsilon$-caprolactone)nanofibers via one-step electrospinning and their cytotoxicity impact," Colloids and Surfaces A, vol. 431, pp. 1-8, 2013.

[19] F. Croisier, A.-S. Duwez, C. Jérôme et al., "Mechanical testing of electrospun PCL fibers," Acta Biomaterialia, vol. 8, no. 1, pp. 218-224, 2012.

[20] A. K. Jaiswal, H. Chhabra, S. S. Kadam, K. Londhe, V. P. Soni, and J. R. Bellare, "Hardystonite improves biocompatibility and strength of electrospun polycaprolactone nanofibers over hydroxyapatite: a comparative study," Materials Science and Engineering C, vol. 33, no. 5, pp. 2926-2936, 2013. 

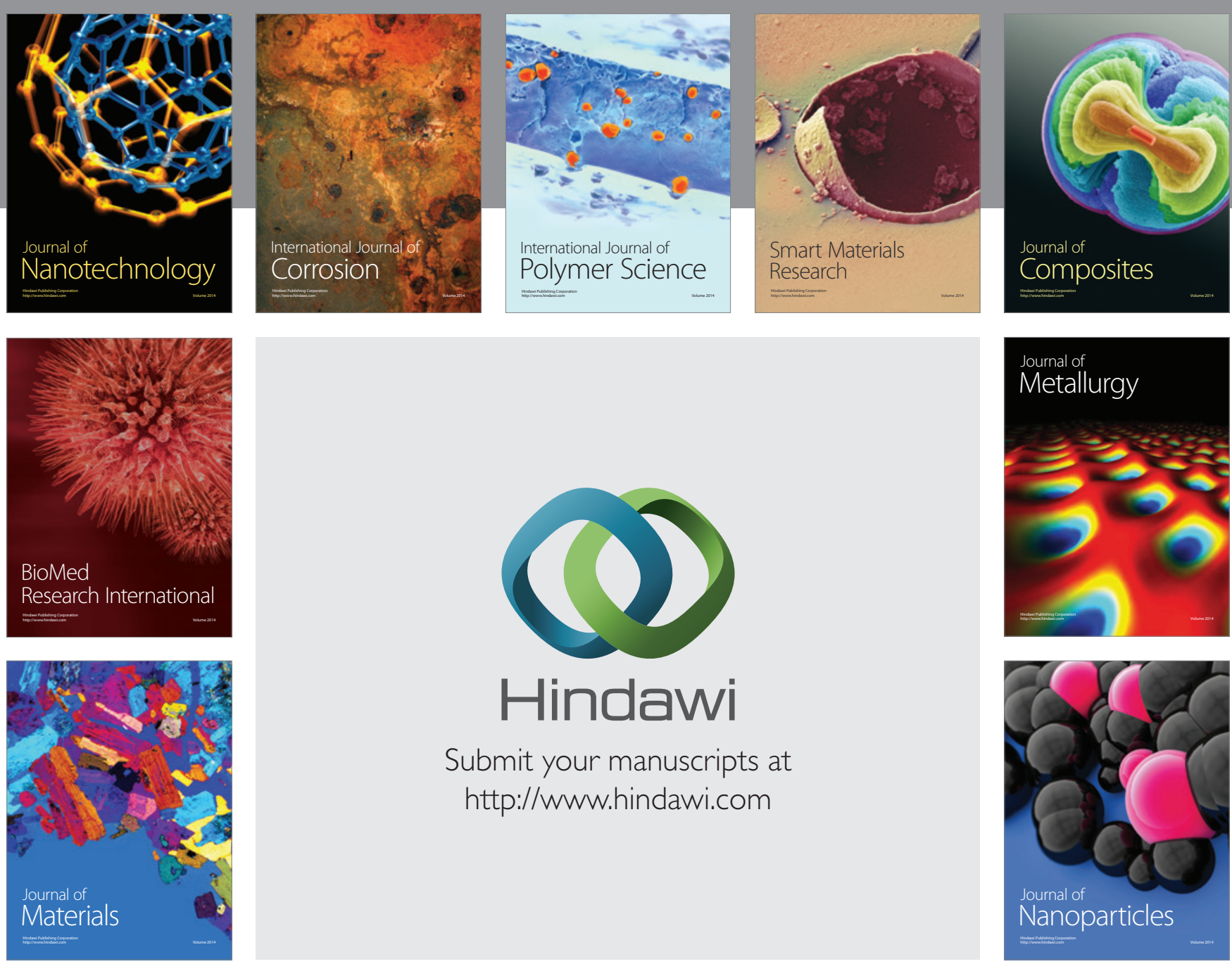

Submit your manuscripts at http://www.hindawi.com
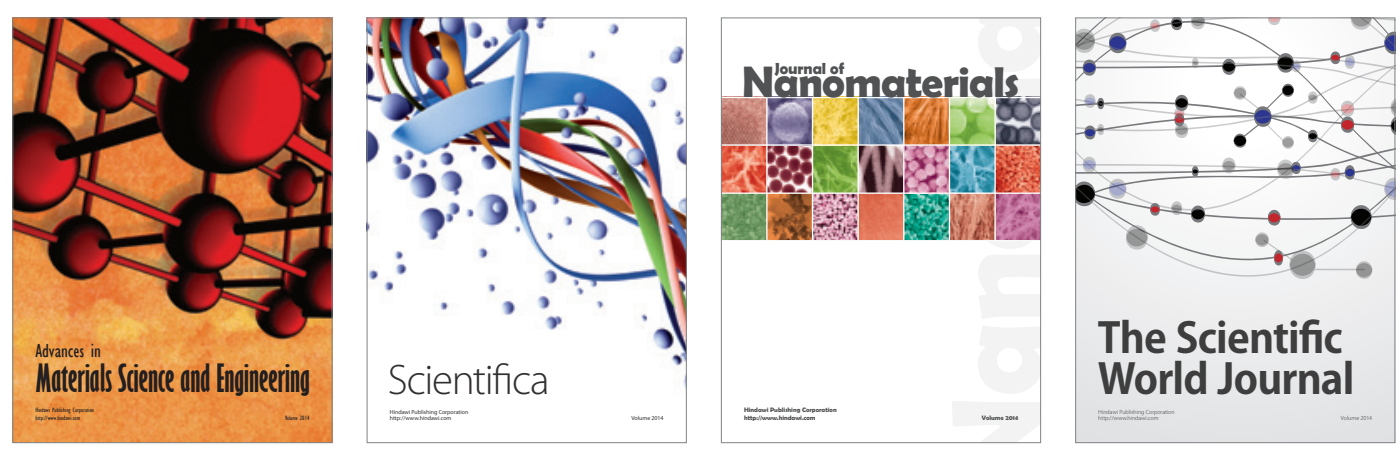

\section{The Scientific World Journal}
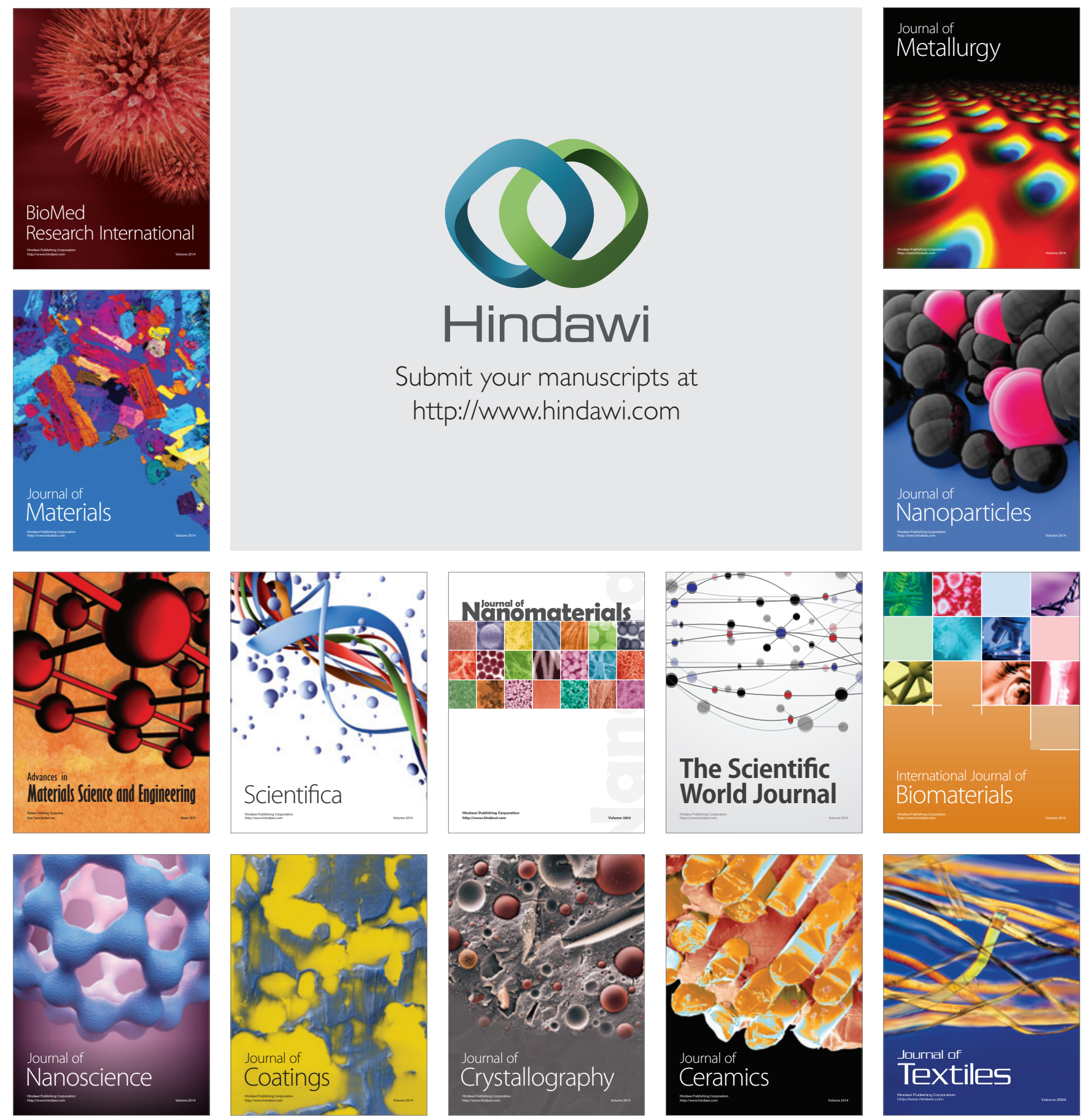